NBER WORKING PAPER SERIES

\title{
PRICE SALIENCE AND PRODUCT CHOICE
}

\author{
Thomas Blake \\ Sarah Moshary \\ Kane Sweeney \\ Steven Tadelis \\ Working Paper 25186 \\ http://www.nber.org/papers/w25186 \\ NATIONAL BUREAU OF ECONOMIC RESEARCH \\ 1050 Massachusetts Avenue \\ Cambridge, MA 02138 \\ October 2018
}

We are grateful to executives and employees at Stubhub for sharing the data for this study. We thank numerous seminar participants for helpful comments. The views expressed herein are those of the authors and do not necessarily reflect the views of the National Bureau of Economic Research.

At least one co-author has disclosed a financial relationship of potential relevance for this research. Further information is available online at http://www.nber.org/papers/w25186.ack

NBER working papers are circulated for discussion and comment purposes. They have not been peer-reviewed or been subject to the review by the NBER Board of Directors that accompanies official NBER publications.

(C) 2018 by Thomas Blake, Sarah Moshary, Kane Sweeney, and Steven Tadelis. All rights reserved. Short sections of text, not to exceed two paragraphs, may be quoted without explicit permission provided that full credit, including $\left({ }^{\circ}\right.$ notice, is given to the source. 
Price Salience and Product Choice

Thomas Blake, Sarah Moshary, Kane Sweeney, and Steven Tadelis

NBER Working Paper No. 25186

October 2018

JEL No. C93,D12,D83,L11

\begin{abstract}
$\underline{\text { ABSTRACT }}$
We study the effect of price salience on whether a product is purchased and, conditional on purchase, the quality purchased. Consistent with our theoretical predictions, we find that making the full purchase price salient to consumers reduces both the quality and quantity of goods purchased. The effect of salience on quality accounts for at least $28 \%$ of the overall revenue decline. Evidence shows that the effects persist beyond the first purchase and impact even experienced users. Detailed click-stream data shows that price-obfuscation makes price comparisons difficult and results in consumers spending more than they otherwise would. We also find that sellers respond to the increased price obfuscation by listing higher quality tickets.
\end{abstract}

Thomas Blake

eBay Research Labs

2065 Hamilton Ave

San Jose, CA 94125

tomblake@gmail.com

Sarah Moshary

University of Chicago Booth

School of Business

$5807 \mathrm{~S}$ Woodlawn Ave

Chicago, IL 60637

Sarah.moshary@chicagobooth.edu

\author{
Kane Sweeney \\ Uber, Marketplace Optimization \\ 1455 Market St \#400 \\ San Francisco, CA 94103 \\ kanesweeney@gmail.com \\ Steven Tadelis \\ Haas School of Business \\ University of California, Berkeley \\ 545 Student Services Building \\ Berkeley, CA 94720 \\ and NBER \\ stadelis@haas.berkeley.edu
}




\section{Introduction}

Textbook models of consumer choice assume that economic agents are fully rational and sophisticated in their ability to discern a product's true price, including fees, taxes, and possible add-on features. However, a growing literature demonstrates that consumers often struggle to determine final prices. For example, Chetty et al. (2009) document that tax salience affects consumers' decisions to purchase personal care goods in grocery stores, implying that consumers have trouble inferring final prices when taxes are not displayed on the shelf. Morowitz et al. (1998) find that students in a lab react less to surcharges presented as percentages rather than dollars, suggesting a cognitive difficulty in calculating prices. Hossain and Morgan (2006) present evidence that eBay buyers respond more to list price than to shipping cost.1 1

In this paper, we employ a large-scale field experiment to show that price salience not only affects a consumer's decision to purchase any product, but also which product to purchase. To illustrate our approach, consider the case of a percentage fee levied on all goods in a market. Price salience affects consumers along two margins. First, increasing salience makes all goods appear more expensive, impacting the extensive margin by leading more consumers to opt out of the market. Second, because a percentage fee levies a larger fee level for more expensive goods, salience changes the perceived marginal cost of quality. As a result, increasing salience encourages the consumer to substitute towards cheaper, lower-quality goods. The contribution of our paper is to offer a more complete analysis of the effect of price salience on consumers' choices by quantifying the importance of both margins..$^{2}$

\footnotetext{
${ }^{1}$ See also Brynjolfsson and Smith (2001) and Sullivan (2017), who considers resort fees and hotel rates. In a related vein exploring choices that are more demanding on cognition, Allcott and Taubinsky (2015) find that consumers underestimate the cost savings from choosing energy efficient lightbulbs, and Abaluck and Gruber (2011) find that seniors place more weight on medical plan premiums than on expected out-of-pocket costs. See DellaVigna (2009) for an overview the literature.

${ }^{2}$ In their working paper version, Chetty et al. (2009) note that the revenue effect is bigger than the quantity effect, which is potentially due to consumers switching to lower priced items. Their data is insufficient to investigate that possibility further.
} 
We begin our analysis by developing a simple model of consumer choice in the spirit of Bordalo et al. (2013), which illustrates the impact of price salience on purchase decisions. The model demonstrates that if prices are made more salient - i.e., fees are listed clearly upfront - then consumers are not only less likely to purchase any good, but conditional on purchasing, they purchase lower quality goods.

We take these predictions to data generated from a large-scale field experiment conducted by StubHub, a leading online secondary ticket marketplace. Before the experiment was launched in August 2015, the platform used an Upfront Fee (UF) strategy, where the site showed consumers the final price including fees and taxes from their very first viewing of ticket inventory. The platform then experimented with a Back-end Fee (BF) strategy, where fees (such as shipping and handling) were shown only after consumers had selected a particular ticket and proceeded to the checkout page.

StubHub randomly selected $50 \%$ of users for the UF experience, while the remaining $50 \%$ chose tickets based on the seller's listing price, while the fee-inclusive price only appeared at the final checkout process. This provides exogenous variation in fee salience in a setting where we can collect detailed data on consumer choices, including choice sets, signals of purchase intent (e.g. product selection and clicks toward checkout), and final purchases. These rich data allow us to infer the effect of salience on both the extensive and intensive margins of product choice. Our empirical results support the model's predictions: price obfuscation distorts both quality and quantity decisions. A simple lower-bound estimate shows that the intensive margin accounts for at least $28 \%$ of the increase in revenue raised from Back-end Fees.

Further analysis of detailed individual-level clickstream data suggests that Back-end Fees play on consumer misinformation. UF users are more likely to exit before exploring any ticket, while BF users differentially exit at checkout, when they first see the fee. Furthermore, BF users go back to examine other 
listings more often than their UF counterparts. They are more likely to go back multiple times, which suggests that Back-end Fees make price comparisons difficult. Finally, Back-end Fees affect even experienced users, although on a smaller scale, which is consistent with consumers facing optimization costs even when they anticipate a fee, as in Morowitz et al. (1998).

Last, we investigate how sellers who list on Stubhub respond to the change in fee salience across the platform following the experiment's conclusion. Because the platform shifted entirely to the BF experience, which causes buyers to purchase more tickets, and in particular more expensive tickets, the two-sided nature of the platform should influence sellers to list more expensive, higher quality tickets. Using row-numbers as a proxy for quality, our analysis shows that sellers indeed choose to list higher quality tickets after the transition to the BF experience. Hence, consistent with Ellison and Ellison (2009), we find that sellers respond to the change in buyer experience.

As a robustness check, we present evidence on price salience from an earlier experiment at StubHub performed in 2012, when the default user experience was BF. This second experiment randomized at the event- rather than userlevel, and therefore suffers from a separate set of vulnerabilities. Reassuringly, the results are broadly consistent with our findings from the 2015 experiment.

Our paper also contributes to studies of alternative methods of obfuscation, such as add-on pricing and partitioned pricing. Ellison (2005) and Gabaix and Laibson (2006) explore models where some consumers ignore the price of complimentary goods (e.g. parking at a hotel) when making purchase decisions. Predictions from these models have been examined in recent empirical work, such as Ellison and Ellison (2009) and Seim et al. (2017). In the language of Gabaix and Laibson (2006), StubHub fees constitute surcharges rather than add-ons because they are unavoidable. Rather, we might interpret the StubHub fee as a form of partitioned pricing because it is broken out from the base price of the ticket (see Greenleaf et al. (2016) for a review of the 
partitioned pricing literature.) One interpretation of our findings is that salience amplifies the effect of partitioned pricing. Salience may therefore help explain the persistence of markups and price dispersion in online markets, as documented by Brynjolfsson and Smith (2001), among others.

The next section presents a simple model of price salience and derives empirical implications. Section 3 discusses the experiment run at StubHub, as well as the data used in the analysis. Section 4 describes robustness checks on the randomization, while section 5 presents our main results. Section 6 contains evidence on mechanisms and section 7 offers robustness checks based on a second experiment. Section 8 concludes.

\section{A Model of Consumer Choice with Limited Fee Salience}

Consider a consumer who makes purchase decisions under two regimes. In the first, which we call Upfront Fees (UF), the final purchase price including all fees is shown to consumers when they browse the set of available tickets. In the second, which we call Back-End Fees (BF), consumers observe only list prices when they browse available products, and fees are revealed only after a particular ticket is selected for purchase.

First, we consider a consumer's choice when she observes fees upfront. She is presented with a convex and compact set of available tickets $J$, where her utility $v_{j}$ from ticket $j \in J$ depends on its price $p_{j}$ and quality $q_{j}$ (e.g. section and row, delivery method, etc.) as follows:

$$
v_{j}=\theta q_{j}-p_{j}
$$

The consumer's willingness to trade off quality for money is captured by her type $\theta \in[0, \bar{\theta}]$. Let 0 denote the outside option, with $q_{0}=p_{0}=0$. Figure 1 illustrates her optimization problem: the set $J$ of available tickets lies on and above the curved line, and the dashed line $v_{0}=0$ marks the consumer's 
Figure 1: Optimal Ticket Choice

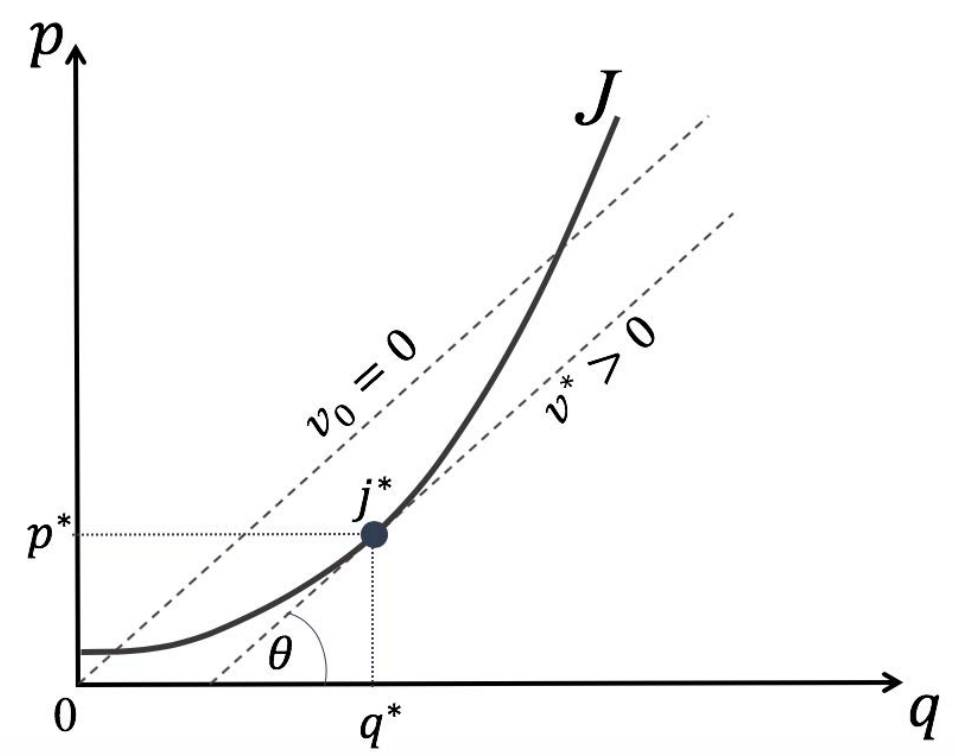

indifference curve from not purchasing. The consumer chooses the ticket $j^{*} \in J$ on her highest indifference curve, yielding a utility of $v^{*}>0$. A higher $\theta$ consumer will purchase a higher quality ticket at a higher price. For consumers with low enough values of $\theta$ (less steep indifference curves in Figure 1), their indifference curve $v_{0}=0$ lies fully below the set $J$, and they will not purchase any ticket. It therefore follows that given a set of tickets $J$, there exists a threshold type $\underline{\theta}>0$ such that a consumer of type $\theta$ will purchase a ticket if and only if $\theta>\underline{\theta}$.

We model consumer optimization with Back-end Fees as a shift in the boundary of $J$. Namely, her choice now depends on the perceived price $\tilde{p}_{j}$ of ticket $j$ rather than its true final price. This is akin to reducing the salience of prices relative to quality as in Bordalo et al. (2013) and is also similar to the way Finkelstein (2009) models salience. The consumer then selects $j \in J$ to solve her optimization problem:

$$
\max _{j \in J} \tilde{v}_{j}=\max _{j \in J} \theta q_{j}-\tilde{p}_{j}
$$

where the perceived price of not purchasing a ticket is also zero, $\tilde{p}_{0}=p_{0}=0$. 
Figure 2: Optimal Ticket Choice

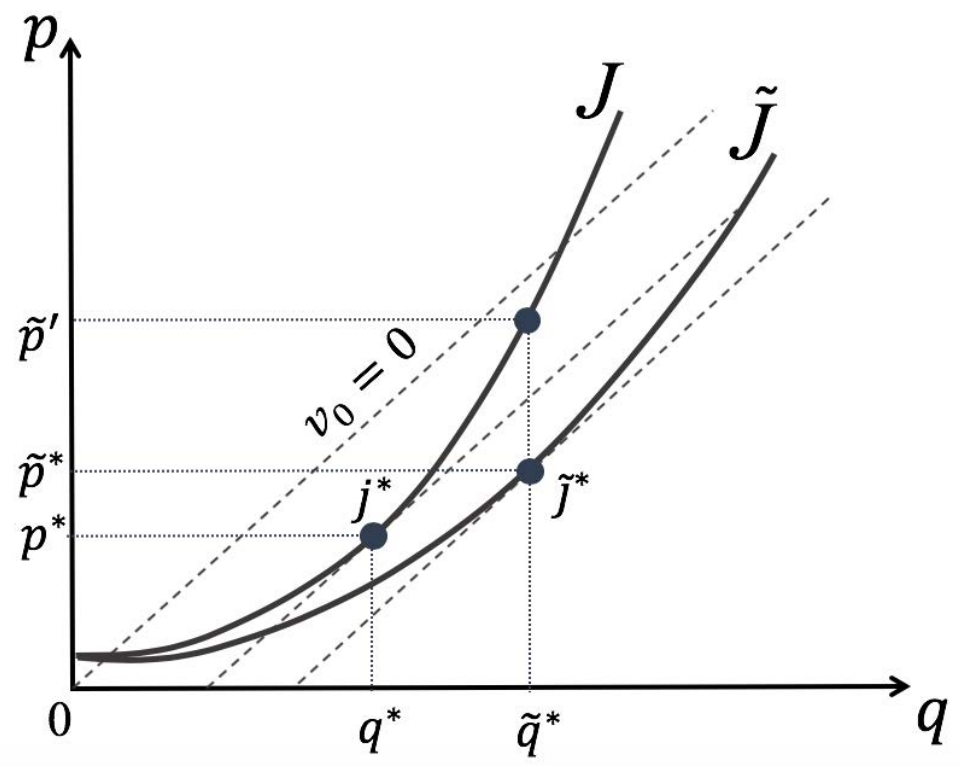

The established view on price salience is that $\tilde{p}_{j}<p_{j}$. That is, when fees are obfuscated, prices appear lower to consumers than they actually are, as illustrated in Figure 2. The true price-quantity frontier is still $J$, however when the consumer chooses a ticket for purchase she perceives the frontier to be $\tilde{J}$, choosing the ticket $\tilde{j}^{*}$ which has quality $\tilde{q}^{*}$ and perceived price $\tilde{p}^{*}$.

Upon reaching the checkout and purchase phase, the ticket's actual priceincluding all fees - is revealed to be $\tilde{p}^{\prime}>\tilde{p}^{*}$. We assume, however, that the consumer will continue with the purchase at this final stage of the purchase funnel rather than go back to the selection stage with a newfound understanding that the true choice set is $J .3$

Recall that the set of consumers with $\theta<\underline{\theta}$ will prefer not to purchase if they perceive the set of tickets to be $J$. Some of these consumers, however, will select a ticket for purchase if they perceive the set of tickets to be $\tilde{J}$. It follows immediately that there exists a threshold type $\underline{\tilde{\theta}} \in[0, \underline{\theta}]$ such that a consumer of type $\theta$ will purchase a ticket if and only if $\theta>\underline{\tilde{\theta}}$. Hence, the

\footnotetext{
${ }^{3}$ Several frictions could prevent consumers who reach checkout from going back to purchase a different ticket, such as loss aversion or the anticipation of re-optimization costs (e.g. having to calculate the fee for each set of tickets). We remain agnostic as to which of these best explain why consumers do not re-optimize, which is what we find in the data.
} 
analysis above implies that fee obfuscation has two effects on consumer choice:

(1) Quantity Effect: Under the Back-end Fee treatment, a consumer is more likely to purchase.

This prediction is consistent with the existing literature: more salient fees reduce the likelihood of purchase. However, it precludes at least two alternative effects of salience: first, if consumers anticipate fees (or hold unbiased beliefs) then perceived prices may not be lower than actual prices. Second, it is also possible that price obfuscation generates a "disgust" factor, wherein last-minute fees upset consumers. In that case, the quantity effect could be negative, contravening the standard price salience model.

When true final prices are higher than perceived prices and the difference is increasing in the listing price, then the model generates a second prediction: customers buy higher quality items than they would under the Upfront Fee regime. This condition would be satisfied, for example, if consumers simply ignored or underestimated a proportional fee or tax. More formally, for any ticket $j$, let $\tilde{p}_{j}$ be the perceived BF price excluding fees and let $p_{j}^{\prime}$ be the true final price observed at checkout. We have,

(2) Quality Upgrade Effect: If $p_{j}^{\prime}-\tilde{p}_{j}>0$ and $p_{j}^{\prime}-\tilde{p}_{j}$ is increasing in $q_{j}$, then consumers buy higher quality tickets under BF.

Conditional on purchasing, consumers upgrade to higher quality tickets under Back-end Fees and therefore spend more on the site. The earlier salience literature overlooks this effect, perhaps because previously studied settings offered little vertical product differentiation (e.g. Electronic Toll Collection systems as in Finkelstein (2009) or supermarket beauty aids as in Chetty et al. (2009) ). Indeed, the log-log demand specification favored by earlier work leaves no scope for quality upgrades.

The Quality Upgrade Effect emphasizes how identification strategies must 
respect the impact of salience on quality choice. Consider the alcohol sales analysis of Chetty et al. (2009). They compare an excise (lump sum) tax to a sales (percentage) tax. The excise tax should arguably not effect the quality of beer chosen (conditional on purchase), since it makes each can of beer "in the choice set" more expensive by the same amount. The sales tax, however, may affect both the quantity and quality margins, since it is a percentage of the price. Simple comparisons of the revenue effects of excise and sales tax salience may therefore lead to inconclusive results.

The next section elaborates our empirical strategy for separately estimating the quantity effect, bounds on the quality upgrade effect, revenue effects, and the change in the average purchase price.

\section{$3 \quad$ Experimental Design}

We exploit an experiment in price salience performed on StubHub, a platform for secondary market ticket sales. Between 2013 and 2015, the platform showed all fees upfront, so the initial price a consumer saw when browsing ticket inventory was the final checkout price. Between August 19 and August 31 of 2015, the firm ran an experiment where treated consumers were initially shown ticket prices without fees.4 For treated customers, fees were added at the checkout page, much like taxes at the register of a store. We refer to this user experience as Back-end Fees..$^{5}$ StubHub's fee structure is non-linear: the buyer fee is $15 \%$ of the ticket price plus shipping and handling, if applicable. StubHub also charges seller fees, which peak at $15 \%$.

The experimental condition was assigned at the cookie-level, which identifies a browser on a computer. Half of site visitors were assigned to the treatment (BF) group at their first touch of an event page. On the event page, users are shown a list of tickets. Consumers assigned to the pre-experimental UF

\footnotetext{
${ }^{4}$ Ethan Smith, "StubHub Gets Out of All-In Pricing." Wall Street Journal, August 31, 2015.

${ }^{5}$ Ticketmaster and other platforms also employ a similar Back-End Fee pricing scheme.
} 
experience (the control group) were shown conspicuous onsite announcements confirming that the prices they saw upfront included all charges and fees. On the other hand, treated users in the BF group were shown only the base price when they perused available listings. Once a user in the BF group selected a ticket, they were taken to a ticket details page, where they could log in to purchase the ticket and then review the purchase. It is at this point that the BF group was shown the total price (ticket cost plus fees and shipping charges). Users could then checkout or abandon the purchase.

First, we exploit the randomization to estimate the quantity effect described in section 2. Let $Q_{i}$ be an indicator that consumer $i$ purchases a ticket, and let $T_{i}$ be a $\mathrm{BF}$ treatment indicator. The quantity effect is the difference in the likelihood of purchase between UF and BF users:

$$
\Delta Q=E\left[Q_{i} \mid T_{i}=1\right]-E\left[Q_{i} \mid T_{i}=0\right]
$$

Because sellers on StubHub cannot price discriminate between BF and UF users, we need not worry that the two groups face different prices because of the treatment (nor do we include other control variables). In practice, we estimate the following regression equation via OLS,

$$
Q_{i}=\alpha+\beta T_{i}+\epsilon_{i}
$$

where $\beta$ represents the difference in the levels of $Q_{i}$ for BF compared to UF users. To protect business-sensitive information, however, we report estimates of $\frac{\beta}{\alpha}$, which is the percent change in the likelihood of purchase for BF users.

Measuring the Quality Upgrade Effect is challenging because the random assignment of the BF experience changes the marginal consumer. As Figure 2 demonstrates, the marginal consumer who purchases under $\mathrm{BF}$ has a lower $\theta$, and chooses lower quality tickets. Measuring the Quality Upgrade Effect needs to adjust for this selection. Namely, conditional on $i$ making a purchase, let $P_{i}$ 
be the purchase price of the ticket that $i$ selects. Let $Q_{i 0}$ be an indicator for whether consumer $i$ purchases a ticket when he observes fees upfront $\left(T_{i}=0\right)$ and $Q_{i 1}$ for when he observes fees at the back-end $\left(T_{i}=1\right)$. We formulate the Quality Upgrade Effect using the potential outcomes notation as:

$$
\mathrm{QUE}=E\left[P_{i} \mid Q_{i 0}=1, T_{i}=1\right]-E\left[P_{i} \mid Q_{i 0}=1, T_{i}=0\right]
$$

The second term is observed by the econometrician and is the average price of tickets purchased by UF users. The challenge is that the econometrician cannot observe the first term, which is the average price of tickets UF users would buy if they were exposed to the BF treatment. Instead, we observe the change in the average price, conditional on purchasing:

$$
\begin{aligned}
\Delta P & =E\left[P_{i} \mid Q_{i 1}=1, T_{i}=1\right]-E\left[P_{i} \mid Q_{i 0}=1, T_{i}=0\right] \\
& =\text { QUE }+E\left[P_{i} \mid Q_{i 1}=1, T_{i}=1\right]-E\left[P_{i} \mid Q_{i 0}=1, T_{i}=1\right] \\
& \leq \text { QUE. }
\end{aligned}
$$

$\Delta P$ constitutes a lower bound for the Quality Upgrade Effect because of the change in the marginal consumer, and the standard monotonicity of choice for a given consumer of type $\theta$ (i.e., $\left.\operatorname{Pr}\left\{Q_{i 1}=1 \mid Q_{i 0}=1\right\}=1\right) . \Delta P$ combines two separate effects: first, the Quality Upgrade Effect, where BF encourages consumers to purchase more expensive tickets than they would otherwise, and second, a change in the marginal consumer, as BF induces more consumers to purchase tickets (the types $\theta \in[\underline{\theta}, \underline{\theta}]$ ). The former increases the average purchase price while the latter depresses it in the BF group because the marginal consumers $\theta \in[\underline{\tilde{\theta}}, \underline{\theta}]$ buy cheaper tickets. $\Delta P$ is therefore a lower bound for the Quality Upgrade Effect. We estimate (4) using regression specification (2) with price as the left-hand side variable.

We derive an upper bound for the Quality Upgrade Effect by setting the purchase price among marginal consumers to zero. That is, we assume that 
users who buy under BF but abstain under UF get tickets for free under the $\mathrm{BF}$ treatment. Formally, consider the following expression for $\Delta P$,

$$
\begin{aligned}
& \Delta P=E\left[P_{i} \mid Q_{i 1}=1, T_{i}=1\right]-E\left[P_{i} \mid Q_{i 1}=1, T_{i}=0\right] \\
& =E\left[P_{i} \mid Q_{i 1}=1, T_{i}=1, Q_{i 0}=1\right] \cdot \operatorname{Pr}\left\{Q_{i 0}=1 \mid Q_{i 1}=1\right\} \\
& +E\left[P_{i} \mid Q_{i 1}=1, T_{i}=1, Q_{i 0}=0\right] \cdot \operatorname{Pr}\left\{Q_{i 0}=0 \mid Q_{i 1}=1\right\} \\
& -E\left[P_{i} \mid Q_{i 0}=1, T_{i}=0\right] \\
& =E\left[P_{i} \mid Q_{i 1}=1, T_{i}=1\right] \cdot \frac{\operatorname{Pr}\left\{Q_{i 0}=1\right\}}{\operatorname{Pr}\left\{Q_{i 1}=1\right\}} \\
& +E\left[P_{i} \mid Q_{i 1}=1, T_{i}=1, Q_{i 0}=0\right] \cdot\left(1-\frac{\operatorname{Pr}\left\{Q_{i 0}=1\right\}}{\operatorname{Pr}\left\{Q_{i 1}=1\right\}}\right) \\
& -E\left[P_{i} \mid Q_{i 0}=1, T_{i}=0\right] \\
& +E\left[P_{i} \mid Q_{i 0}=1, T_{i}=0\right] \cdot \frac{\operatorname{Pr}\left\{Q_{i 0}=1\right\}}{\operatorname{Pr}\left\{Q_{i 1}=1\right\}}-E\left[P_{i} \mid Q_{i 0}=1, T_{i}=0\right] \cdot \frac{\operatorname{Pr}\left\{Q_{i 0}=1\right\}}{\operatorname{Pr}\left\{Q_{i 1}=1\right\}} \\
& =\mathrm{QUE} \cdot \frac{\operatorname{Pr}\left\{Q_{i 0}=1\right\}}{\operatorname{Pr}\left\{Q_{i 1}=1\right\}}-E\left[P_{i} \mid Q_{i 0}=1, T_{i}=0\right] \cdot\left(1-\frac{\operatorname{Pr}\left\{Q_{i 0}=1\right\}}{\operatorname{Pr}\left\{Q_{i 1}=1\right\}}\right) \\
& +\underbrace{E\left[P_{i} \mid Q_{i 1}=1, T_{i}=1, Q_{i 0}=0\right] \cdot\left(1-\frac{\operatorname{Pr}\left\{Q_{i 0}=1\right\}}{\operatorname{Pr}\left\{Q_{i 1}=1\right\}}\right)}_{>0}
\end{aligned}
$$

The first equality follows from a conditional probability decomposition of $E\left[P_{i} \mid Q_{i 1}=1, T_{i}=1\right]$. The second equality follows from choice monotonicity, which implies that $\operatorname{Pr}\left\{Q_{i 0}=1 \mid Q_{i 1}=1\right\}=\frac{\operatorname{Pr}\left\{Q_{i 0}=1\right\}}{\operatorname{Pr}\left\{Q_{i 1}=1\right\}}$, and we add and subtract an additional term to create a term including QUE. The last equality contains three expressions, the last of which includes the expected price of tickets bought by the marginal users who buy under BF but abstain under UF (the types $\theta \in[\underline{\tilde{\theta}}, \underline{\theta}])$, which we cannot observe but is greater than zero. If we assume that these consumers buy at a price of zero, therefore setting this last term to zero, we obtain the following upper bound on QUE:

$$
\mathrm{QUE} \leq \Delta P \cdot \frac{\operatorname{Pr}\left\{Q_{i 1}=1\right\}}{\operatorname{Pr}\left\{Q_{i 0}=1\right\}}+E\left[P_{i} \mid Q_{i 0}=1, T_{i}=0\right] \cdot\left(\frac{\operatorname{Pr}\left\{Q_{i 1}=1\right\}}{\operatorname{Pr}\left\{Q_{i 0}=1\right\}}-1\right)
$$


Importantly, all of the terms on the left-hand-side in equation (5) can be estimated directly from the data.

We note that the change in average purchase price is inherently interesting in this setting, as it maps to a change in platform revenue. We decompose expected revenue using conditional probability as:

$$
E\left[R_{i}\right]=E\left[P_{i} \mid Q_{i}=1\right] \cdot \operatorname{Pr}\left\{Q_{i}=1\right\}=E\left[P_{i} \mid Q_{i}=1\right] \cdot E\left[Q_{i}\right]
$$

and the change in revenue from treatment is

$$
\Delta E\left[R_{i}\right]=\underbrace{\Delta E\left[P_{i} \mid Q_{i}=1\right]}_{\Delta P} \cdot E\left[Q_{i}\right]+\underbrace{\Delta E\left[Q_{i}\right]}_{\Delta Q} \cdot E\left[P_{i} \mid Q_{i}=1\right] .
$$

\section{Randomization Check}

The experiment included several million users who visited the site over ten days. To check randomization, we test whether we can reject a $50 \%$ treatment assignment probability. Results are shown in Table 1. While the odds of assignment to the treatment group are $50.11 \%$ in the full sample, the large scale of the experiment allows us to reject the null hypothesis of a $50 \%$ assignment probability at the $5 \%$ level. Upon closer scrutiny, we discovered two glitches in the randomization: first, all users who logged in during the first 30 minutes of the experiment were assigned to the treatment group. Second, users on a particular browser-operating system combination were also skewed to the treatment group. After eliminating these two groups we can no longer reject a $50 \%$ assignment at the $1 \%$ level..$^{6}$ We therefore exclude these users in our main analysis.7 Although the probability of treatment remains slightly above $50 \%$, the difference is economically insignificant.

As a robustness check on randomization, we test whether UF and BF users

\footnotetext{
${ }^{6}$ Or at the $5 \%$ level in a one-sided test against the null that the treatment assignment is $>50 \%$.

${ }^{7}$ However, our main results are robust to their inclusion in the sample.
} 
Table 1: Treatment Assignment

\begin{tabular}{lcccc}
\hline \hline Sample & \% Unidentified & \% Site in Sample & \% Back-end Fees & T-statistic \\
Full & $0.78 \%$ & $100 \%$ & $50.11 \%$ & 4.28 \\
Time Restriction & $0.78 \%$ & $99.82 \%$ & $50.09 \%$ & 3.41 \\
$\begin{array}{l}\text { Time \& Browser } \\
\text { Restriction }\end{array}$ & $0.82 \%$ & $66.12 \%$ & $50.06 \%$ & 1.99 \\
\hline
\end{tabular}

Notes: This table reports the assignment of StubHub users (cookies) to different treatment cells. Each row corresponds to a different sample restriction. The T-statistics is from a two-sided test with a null of a $50 \%$ assignment probability.

Table 2: Covariate Balance

\begin{tabular}{lcc}
\hline \hline User Characteristic & \% Difference & T-statistic \\
\hline Experience & 0.01 & 0.02 \\
Hour & -0.08 & -1.6 \\
Mac User & 0.16 & 0.01 \\
\hline
\end{tabular}

Notes: This table presents summary statistics for differences between the BF (treatment) and UF (control) groups in our experiment from August 19 - 31, 2015.

share similar observable characteristics. Unfortunately, as treatment was assigned before users are required to log-in, the set of observables is limited. For example, we observe a user's purchase history only if they log on to the site during the experiment or if they have not cleared their cookies after a recent visit. However, we do see site visits since the last cookie-reset, which we use to measure experience. We use this proxy as a left-hand side variable in specification (1). Row 1 of Table 2 shows that the two groups have almost identical experience levels. BF and UF users also visit the site at similar hours-of-the-day, and are equally likely to use mac computers (rows 2 and 3). These results give us confidence that the randomization was successful. 


\section{Results}

Theory indicates that obfuscation should encourage consumers on the margin (low values of $\theta$ ) to switch from the outside option to purchasing a ticket on StubHub, and also encourage consumers to switch from purchasing lower to higher quality tickets. Table 3 column 1 shows the net effect on revenue of the price salience treatment. Consumers identified with cookies in the Back-end Fee group, where fees are shrouded, spend almost $21 \%$ more than those assigned to the Upfront Fee group. We show revenue effects for the session (same-day) and over the entire experiment (10 days), and point estimates are large and statistically significant at the $1 \%$ level for both.

Unfortunately, quantifying salience is difficult, so it is hard to benchmark our estimate to Chetty et al. (2009). (While the change in user experience in the StubHub experiment is similar in spirit to their experiment of adding fees to supermarket shelf prices, it is not clear how closely they align.) They find that obfuscating a $7.35 \%$ tax leads to an $8 \%$ revenue increase. On StubHub, obfuscating a $15 \%$ fee leads to a $21 \%$ revenue boost. .8 Our findings, detailed below, suggest that upgrades augment the salience effect in our setting.

\subsection{Quantity Effect}

We first examine the effect of salience on quantity, as defined in equation (1). The third row of Table 3 shows that price obfuscation increased the transaction rate over the full course of the experiment by $14.1 \%$. The second from last row shows within a cookie-session, consumers in the BF group are $12.43 \%$ more likely to purchase a ticket during a visit (the estimate is significant at the $1 \%$ level). Fees average roughly $15 \%$ of ticket prices, suggesting a per-session salience elasticity of $0.1243 / 0.15=0.87$, which is a similar order of magnitude to the elasticity of 1.1 found in Chetty et al. (2009). The 10-day elasticity

\footnotetext{
${ }^{8}$ Fee documented in: Katy Osborn. September 1, 2015. "Why StubHub is tacking on ticket fees again." The Wall Street Journal.
} 
Table 3: Effect of Salience on Purchasing

\begin{tabular}{lcc}
\hline \hline & \multicolumn{2}{c}{ Back-end vs Upfront Fees \% Difference } \\
\cline { 2 - 3 } & Baseline & Conditional on Purchasing \\
Cookie 10-day & $20.64 \%$ & $5.42 \%$ \\
Revenue & $(1.38)$ & $(1.37)$ \\
Average Seat Price & - & $5.73 \%$ \\
& & $(1.5)$ \\
Propensity to Purchase & $14.1 \%$ & - \\
at Least Once & $(0.09)$ & $-0.9 \%$ \\
\# Transactions within & $13.24 \%$ & $(0.58)$ \\
10 Days & $(0.88)$ & $-2.32 \%$ \\
\# Seats within 10 Days & $11.37 \%$ & $(0.84)$ \\
& $(1.17)$ & $-3.29 \%$ \\
12-Month Churn & - & $(0.66)$ \\
\hline Cookie Session & $18.96 \%$ & $5.61 \%$ \\
Revenue & $(1.27)$ & $(1.27)$ \\
Cookie Session & $12.43 \%$ & - \\
Propensity to Purchase & $(0.6)$ & \\
\hline
\end{tabular}

Notes: This table presents coefficient estimates from equation 2 for different right-hand side measures of purchasing. Heteroskedasticity-robust standard errors are reported in parentheses.

is larger than the session elasticity $(0.141 / 0.15=0.94)$, suggesting that the long-run effects of salience may be even greater.

Table 3 also provides estimates of how salience impacts the number of tickets purchased. Our simple model abstracts from the consumer's decision of how many seats to buy and describes a world where consumers need a fixed number of seats and either buy that exact number or buy none at all. In reality, of course, consumers might enlarge their parties if they perceive prices to be lower. To the contrary, we find that Back-end Fee users buy $2.4 \%$ fewer 
seats, conditional on making at least one purchase at StubHub. Admittedly, this effect is swamped by the increased probability of buying at least one ticket on StubHub, but hints at the nuance in salience responses. The lower number of seats suggests that the marginal consumers lured by the Back-end Fee treatment buy slightly fewer tickets.

\subsection{Quality Upgrade Effect}

The second column of Table 3 compares differences in the Back-end and Upfront Fee groups' behavior conditional on a purchase. This comparison allows us to assess how salience affects average purchase prices: BF users spend $5.42 \%$ more than their UF counterparts. From the platform's perspective, the combination of the Quantity Effect and the Quality Upgrade Effect implies that the effect of salience on their bottom line is substantially larger than suggested in the earlier literature, which did not consider product choice.

Using equation (6) we can calculate the increased revenues that are due separately to the Quantity effect and the Quality Upgrade Effect. From Table 3, we observe that $\Delta P=5.42 P$ and $\Delta Q=14.1 Q$ and hence, rewriting Equation (6) without the expectations operator and subscripts for brevity,

$$
\Delta R=\Delta P \cdot Q+\Delta Q \cdot P=5.42 \cdot Q P+14.1 \cdot Q P .
$$

Dividing both the left- and right-hand sides by revenues, $Q P$, we calculate the percent change in revenues to be $19.52 \%$, of which $5.42 \%$ (about $28 \%$ of increased revenues) are from the Quality Upgrade Effect. Note that the number of seats declines slightly, so that the change in the average purchase price per seat is even greater $(5.73 \%)$.

We interpret the change in purchase price as evidence of an upgrade effect, where shrouding fees leads consumers to buy more expensive, higher quality tickets. This finding is consistent with Lynch and Ariely (2000), who find 
that subjects in a lab experiment buy higher quality wine when prices are not displayed alongside product descriptions (and are only shown at checkout). Our model indicates that the change in the average purchase price constitutes a lower bound for the upgrade effect - and while smaller than the quantity effect, even this lower bound is economically meaningful. Our calculation of the upper bound (5) is $16.52 \%$, suggesting that the Quality Upgrade Effect may even exceed the Quantity Effect.

Figure 3: Difference in Likelihood of Purchase by Row (BF versus UF users)

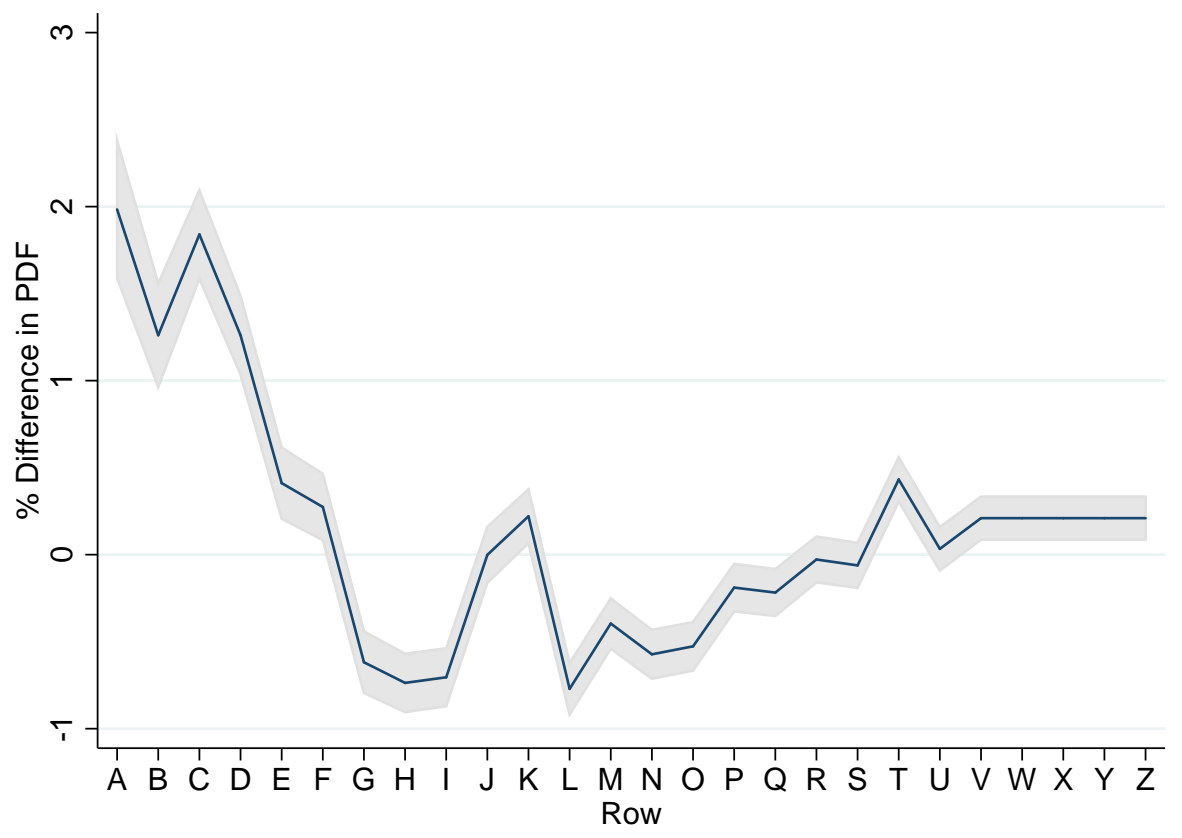

We provide auxiliary evidence on the upgrade effect using data on seat locations. In particular, we examine whether Back-end Fee users buy seats closer to the stage. Rows are often labeled using letters, where letters earlier in the alphabet correspond to a better view.9 Conditional on purchasing a ticket, we separately calculate the probability that a BF and UF user purchases a seat in each row. Figure 3 graphs the relative probability (the ratio of the two probability mass functions), along with $95 \%$ confidence intervals, which are calculated point-wise. Back-end Fee users are relatively more likely to

\footnotetext{
${ }^{9}$ As numbering schemes vary across venues, letter position only proxies for quality.
} 
purchase seats in rows $\mathrm{A}$ through $\mathrm{D}$, which are the very first rows, and the likelihood declines for rows later in the alphabet. These trends provide further evidence of the Quality Upgrade Effect.

\section{Mechanisms}

\subsection{Misinformation}

In this section, we leverage StubHub's detailed data to better understand why fee salience affects consumers so greatly. First, we examine consumer misinformation using web-browsing behavior. If consumers do not anticipate fees, then they will receive a negative surprise at check-out and should be more likely to exit when the fee first appears. For consumers who are nearly indifferent between purchasing at the base ticket price, the fee makes the outside option their utility-maximizing choice. Importantly, a misinformation theory offers implications about where (in the purchase funnel) Back-end and Upfront Fee users will differentially exit.

To buy a ticket, a user follows StubHub's "purchase funnel" on the website as follows: (1) the consumer first sees the event page, which contains a seat map and a sidebar with top ticket results, sorted by price in ascending order; (2) once a consumer clicks on a ticket, the ticket details page appears; (3) the consumer proceeds to the checkout page where a final purchase decision is made; (4) the purchase confirmation page completes the process. ${ }^{10}$ BF users are shown lower prices than their UF peers until stage (3), when they are shown the final price, inclusive of fees. If consumers are ignorant of fees, there should be a larger drop off between stages (1) and (2) for the UF group, since they see higher prices initially. But there should be a larger drop-off between stages (3) and (4) for the BF group. If the former is larger than the latter,

\footnotetext{
${ }^{10}$ Before reaching the Checkout page, a log-in page appears unless the consumer was already logged into their account. Many searches are non-linear, where consumers examine multiple event pages (see Blake et al. (2016)). BF users might even return to stage (1) once they see the additional fees leveed at stage (4).
} 
then Back-end Fees increase the quantity sold.

Table 4: Purchase Funnel Behavior by Fee Salience

\begin{tabular}{|c|c|c|c|c|c|c|}
\hline & \multicolumn{3}{|c|}{ Percentage Click Through from Prior Page } & \multicolumn{3}{|c|}{ Average Ticket Price } \\
\hline & $\underline{\mathrm{BF}}$ & $\underline{\mathrm{UF}}$ & $\underline{\% \text { Difference }}$ & $\underline{\mathrm{BF}}$ & $\underline{\mathrm{UF}}$ & \% Difference \\
\hline Event Page & - & - & - & $\$ 1.00$ & $\$ 0.84$ & $18.73 \%$ \\
\hline Ticket Details & $\begin{array}{l}27.96 \\
(0.01)\end{array}$ & $\begin{array}{l}23.56 \\
(0.01)\end{array}$ & $\begin{array}{c}18.67 \% \\
(0.00)\end{array}$ & $\$ 0.86$ & $\$ 0.78$ & $10.16 \%$ \\
\hline Review \& Submit & - & - & - & $\$ 0.56$ & $\$ 0.52$ & $7.44 \%$ \\
\hline Purchase & $\begin{array}{l}18.52 \\
(0.06)\end{array}$ & $\begin{array}{c}33.41 \\
(0.1)\end{array}$ & $\begin{array}{c}-44.58 \% \\
(0.00)\end{array}$ & $\$ 0.42$ & $\$ 0.39$ & $6.57 \%$ \\
\hline
\end{tabular}

Notes: This table reports means and standard errors (in parentheses) on user behavior in the StubHub purchase funnel. Average ticket prices are normalized by the average price of tickets selected by Back-end Fee users on the Event Page.

The left panel of Table 4 shows the absolute and relative rate of UF and BF user arrivals between these key steps in the purchase process. Consistent with misinformation, Back-end Fee users are almost 19\% more likely to select tickets (transition from stage 1 to 2 ) than Upfront Fee users. The difference is statistically significant at the $1 \%$ level and economically large. In contrast, the drop off rate at the final stage (purchase) is much larger for BF users, as they are almost $45 \%$ less likely to purchase at checkout.

The right panel of Table 4 presents the average selected ticket price at each step in the purchase funnel for a subset of events. The average price of tickets under consideration declines at each step, suggesting that quality also drops. As the theory predicts, UF users always select cheaper tickets than BF users, but the difference narrows as users move closer to purchase. When fees are revealed, the gap is just under $7 \%$ compared to an initial difference of almost $19 \%$. In sum, BF users are more likely to contemplate expensive tickets but when fees are revealed, more of the (potentially surprised) BF users exit than the UF users who see no change in their expected outlay. 
One important question, from both the firm's and a policy maker's perspective, is whether consumers learn about the fees over time. As an example, consumers could act as if they do not anticipate fees in their ticket selection each time they visit the site. In this case, websites stand to gain substantially by shrouding fees. This implication contrasts with a model where consumers anticipate a fee, but do not know the exact level. In a model with learning, once a consumer makes a purchase, she updates her priors on future StubHub fees and does not make the same 'mistake' twice.

To examine learning, we repeat our principal analysis (Table 3) separately by level of user experience. If consumers learn, then experience ought to lessen the response to obfuscation. Of course, experience is endogenous, so experienced users may react differently to salience for other reasons (as an example, they may be higher income). Nonetheless, examining responses across experience groups hints at how learning might work in this setting.

To measure experience, we calculate the number of visits each cookie has made to StubHub prior to the experiment. A 2006 ComScore study found that $31 \%$ of users clear their cookies within 30 days, so we interpret this as a short-term measure of experience. ${ }^{11}$ Unfortunately, we cannot exploit information about logged-in users (like number of past transactions) because log-in is a potential response to our treatment; users who see lower prices initially may be more likely to log in to the website in order to purchase. Our measure does capture the most recent interactions with StubHub, which are likely to be the most relevant for a user's knowledge of the site.

We hypothesize that frequent StubHub users ought to be aware of fees and therefore less sensitive to salience. We split users into three groups: new users (no recorded visits), low experience (1-9 visits), and high experience (10 or more visits). Table 5 shows that the treatment effect is smaller for cookies with at least 10 site visits: the revenue effect is $15 \%$ compared to

\footnotetext{
${ }^{11}$ https://www.comscore.com/Insights/Blog/When-the-Cookie-Crumbles
} 
21\%. These results suggest that salience may be most important in markets where consumers purchase infrequently (for example, real estate or automobile markets). However, effects are still large for the most experienced group (the top $6 \%$ of users), which indicates only limited consumer learning. Because experience is not randomly assigned in the population, we interpret this evidence as suggestive, rather than causal.

Table 5: Salience by User Experience

\begin{tabular}{lccc}
\hline \hline & \multicolumn{3}{c}{$\%$ Difference } \\
\cline { 2 - 4 } & $\frac{\text { New User }}{21.52 \%}$ & $\frac{\text { Low Experience }}{21.80 \%}$ & High Experience \\
User 10-day Revenue & $(0.02)$ & $(0.02)$ & $15.09 \%$ \\
& & & \\
Propensity to Purchase at Least & $15.33 \%$ & $13.68 \%$ & $10.19 \%$ \\
Once & $(0.007)$ & $(0.01)$ & $(0.02)$ \\
& $14.33 \%$ & $13.53 \%$ & $8.81 \%$ \\
\# Transactions within 10 Days & $(0.01)$ & $(0.01)$ & $(0.03)$ \\
& $67 \%$ & $27 \%$ & $6 \%$ \\
\hline \% Sample & & & \\
\hline
\end{tabular}

Notes: This table reports coefficient estimates 2 for users of different experience levels. Heteroskedasticityrobust standard errors in parentheses. See table 3 for pooled estimates.

We examine user churn to understand the long-run effects of salience. If obfuscation preys on misinformation, then marginal BF consumers, who would not purchase if shown fees upfront, may be more likely to abandon StubHub after seeing fees for the first time. Unfortunately, we cannot identify marginal consumers among the pool of BF consumers. We also cannot compare the return rates of all $\mathrm{BF}$ and $\mathrm{UF}$ users, as there is no way to track future purchases of users who do not log-in to the site. Instead, we compare the return rates of $\mathrm{BF}$ and $\mathrm{UF}$ users who purchase during the experiment. As Table 3 shows, BF users are 3.3\% less likely to churn, which is inconsistent with the simple misinformation story. We emphasize caution in interpreting churn, however, as it potentially confounds multiple treatments: BF users may learn about the platform fees when they make a purchase, but they may 
also learn about StubHub's reliability, speed, quality, etc. This additional learning may increase a consumer's likelihood of purchase, even if obfuscation effects are short lived.

As a robustness check, we compare the likelihood of return for consumers who were logged into StubHub before the experiment. We can track these users' purchases after the experiment's conclusion, regardless of whether they made a purchase during the experiment window. The difference between BF and UF return rates drops to $0.65 \%$ and loses statistical significance. While this sample contains consumers with high attachment to StubHub, this comparison also indicates that salience effects persist beyond initial misinformation.

Finally, to shed light on the persistence of salience, we construct a panel dataset that tracks the purchases of BF and UF users over a six month period centered around the experiment window (May 18 through December 1, 2015). We have already established that BF users spend more, conditional on purchasing, during the experiment. On September 1, the entire site switched to $\mathrm{BF}$, so that the only difference between users who had been assigned to BF versus UF is their experience with the back-end fees. If salience effects are short-lived, then we would expect UF users, who now experience back-end fees for the first time, to outspend their BF counterparts who have 10 days of experience. On other hand, if salience effects persist, then the UF-BF difference should dissipate after the experiment, as both groups spend more than they would have in an UF environment. If $i$ denotes the user and $t$ the purchase date, we model purchase price using the following specification:

$$
\begin{aligned}
\ln p_{i t}= & \alpha_{1} \cdot \text { Before }_{t}+\alpha_{2} \cdot \text { During }_{t}+\alpha_{3} \cdot \text { After }_{t} \\
& +\beta_{1} \cdot \text { Before }_{t} \times T_{i}+\beta_{2} \cdot \text { During }_{t} \times T_{i}+\beta_{3} \cdot \text { After }_{t} \times T_{i}+\epsilon_{i t},
\end{aligned}
$$

where Before $_{t}$ is an indicator that the purchase happened before the experiment, and similarly for During ${ }_{t}$ and After $_{t}$. We estimate equation (8) using the sample of users who purchase during the experiment window because 
Figure 4: Spending Before, During, and After the Platform Switch to Back-end Fees

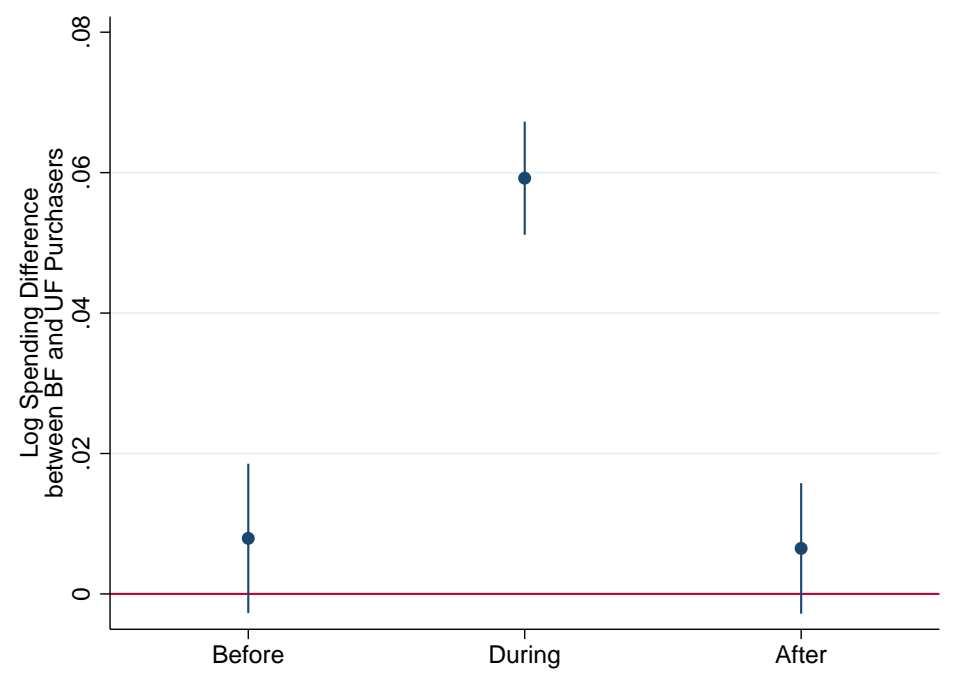

these are the only users we can reliably track. During the purchase process, users log into the site, allowing us to identify their prior and subsequent purchases. We also cluster standard errors at the user level to account for serial correlation in individual purchasing decisions.

Figure 4 displays the estimates of the interactions between the BF treatment indicator and each time period. BF and UF users spend similar amounts before the experiment, when both groups experience UF. As in Table 3, we find that during the experiment, BF users spend almost $6 \%$ more than UF users, conditional on purchasing at least one ticket. However, in the three month period following the experiment, when all users experience BF, there is no difference in spending between the two groups. The results are robust to the inclusion of both buyer and day fixed effects. These event study findings, taken together with our results on experienced users and churn, indicate that salience effects are persistent. They suggest that users do not learn to anticipate the correct fee level after going through the purchase funnel with back-end fees at least once. 
Figure 5: Number of Listings Viewed by Fee Salience

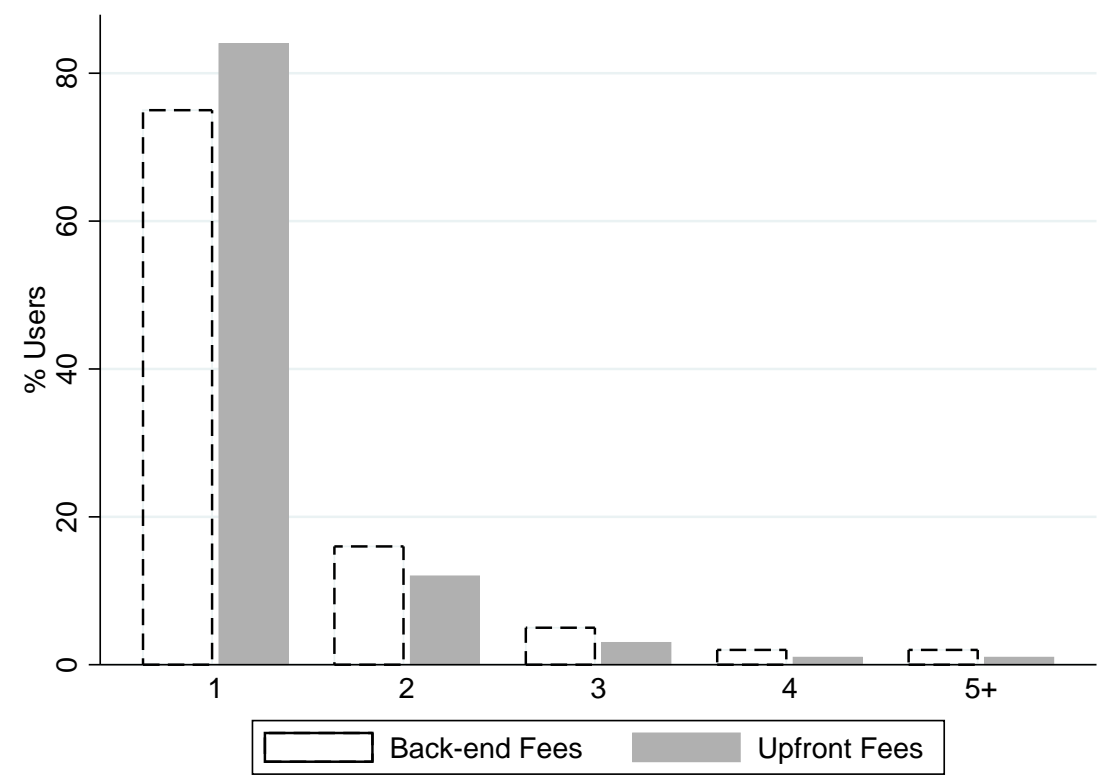

Notes: Pearsons Chi-square of 6700 rejects hypothesis that distribution over rows is same in test and control. (p-value of 0.000 )

\subsection{Consideration Sets and Search Frictions}

In this section, we present evidence on forces beyond misinformation that might contribute to the importance of salience: consideration sets and search frictions. First, we consider whether fee obfuscation widens users' consideration sets. A growing body of literature (e.g. Goeree (2008)) suggests that potential consumers often ignore a large fraction of inventory, and instead focus on choosing between a few products. StubHub presents inventory to consumers in ascending price order, so that expensive tickets are not visible to the consumer unless she actively scrolls down or filters the results (e.g., by section). It is possible that obfuscating fees might draw user attentions to a wider array of products, leading BF users to make different purchase decisions than their UF counterparts. We find that BF users scroll $10 \%$ more often, a difference that is statistically significant at the $1 \%$ level. 
Table 6: Average Price of Tickets Viewed Relative to UF Initial Selections

\begin{tabular}{cccc}
\hline \hline \multicolumn{2}{c}{ Back-end Fees } & \multicolumn{2}{c}{ Upfront Fees } \\
\hline Initial Checkout & Follow-up Actions & Initial Checkout & Follow-up Actions \\
$8.3 \%$ & $0.8 \%$ & $0.0 \%$ & $1.8 \%$ \\
$(1.9)$ & $(1.2)$ & $(-)$ & $(0.6)$ \\
\hline
\end{tabular}

Notes: This table reports means and standard errors for the relative price of tickets viewed across groups. Estimates are normalized by the price of tickets initially brought to check-out by UF users.

When fees are revealed, BF consumers are already at check-out with their tickets, but they may choose to go back to the event page if they wish to re-optimize and purchase cheaper seats. We find that less than a quarter of BF users exercise this option, which is consistent with a search friction beyond misinformation. Figure 5 shows the average number of tickets viewed by $\mathrm{BF}$ and UF users. BF cookies are $56 \%$ more likely to view multiple ticket listing compared to their UF counterparts. Table 6 shows that BF users view cheaper tickets upon their return to the listings page from the checkout page (six percentage points lower). In contrast, UF users, who are less likely to return overall, view more expensive tickets if they do.

Figure 5 shows that $\mathrm{BF}$ users are twice as likely to view three or more listings than their UF counterparts. Viewing more than two tickets suggests the effects of price obfuscation extend beyond an initial confusion about fees. BF consumers who return to the event page have seen fees for their initial selection, but they must calculate the StubHub fee for each new ticket they consider. If calculation costs are high, as hypothesized by Morowitz et al. (1998) or Ellison and Ellison (2009), consumers might choose to go down the funnel multiple times rather than compute the fees themselves. Obfuscation as a search friction is consistent with our findings on experienced customers, who ought to anticipate fees but might still bear a higher search cost when fees are hidden. This evidence is in line with Ellison and Ellison (2009), who find that firms endogenously create such frictions to soften price competition. 
Figure 6: Google Queries for Competing Ticket Resale Platforms

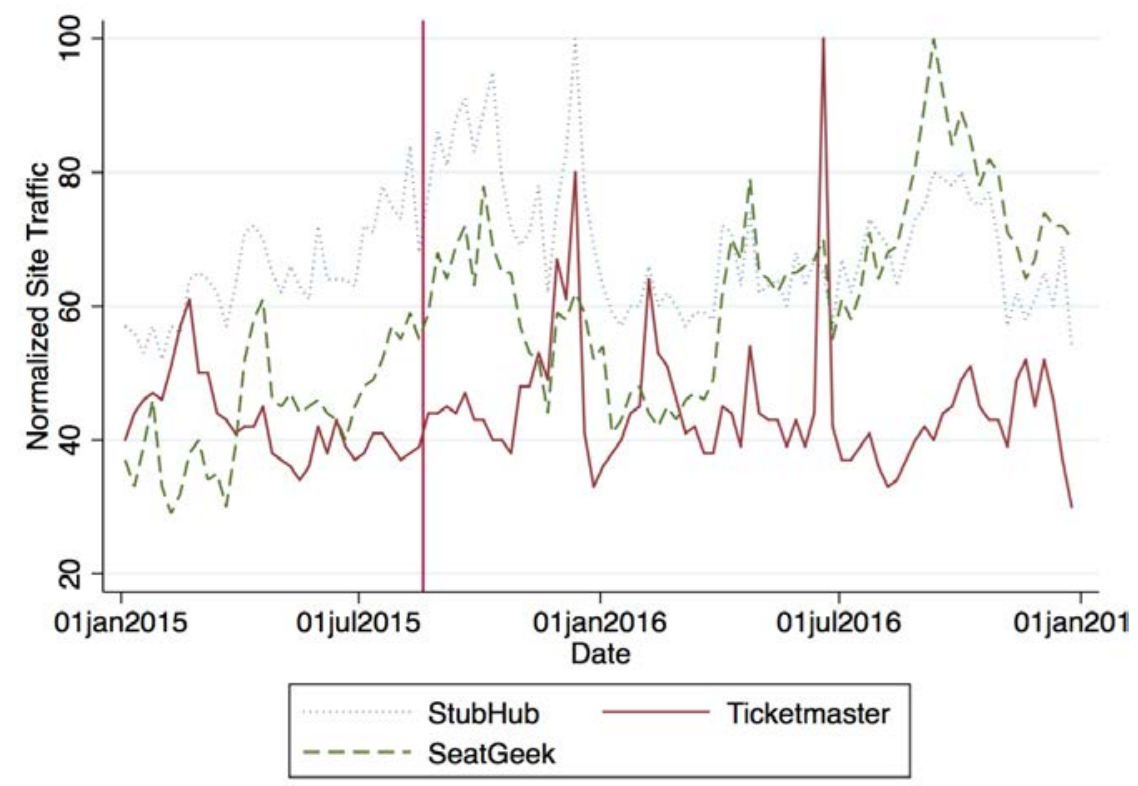

\subsection{Competition with Other Platforms}

Marginal consumers who choose to abandon StubHub may exit the market or they may purchase tickets through a rival platform. Understanding where marginal consumers go has important welfare implications. As an example, if all ticket sellers multi-home, then consumers might buy the same exact tickets on Ticketmaster that they would have under Back-end Fees at StubHub. Obfuscation would then have only limited efficiency consequences (through the product selection margin for users who remain on StubHub). On the other hand, if consumers who leave StubHub under Upfront Fees exit the market, then the change in consumer surplus could be much larger.

To investigate the effect of StubHub's switch to BF, we employ data from GoogleTrends on queries for its main competitors: Ticketmaster and SeatGeek. Both sites act as a secondary market for tickets, with Ticketmaster serving as the primary market for certain sporting and music events. Google provides data on weekly query volume for these sites, but normalizes the data separately for each platform (by dividing by the site's peak over 2012-2017). Figure 
6 shows the evolution of queries for 2015 and 2016. The lift in SeatGeek queries in August 2015 (indicated by a vertical line) suggests that consumers attracted by BF at StubHub do not detract from other sites.

We formally test for a change in Ticketmaster (TM) and SeatGeek (SG) queries using an event-study design akin to (8). We interact indicator variables for each site with indicators for the time period (During $t$ corresponds to the two weeks when the experiment was running and After $_{t}$ corresponds to all weeks thereafter). Our specification is

$$
\begin{aligned}
\log \left(\text { Queries }_{i t}\right) & =\beta_{0}+\beta_{1} \cdot \text { After }_{t}+\beta_{2} \cdot \text { After }_{t} \times T M_{i}+\beta_{3} \cdot \text { After }_{t} \times S G_{i} \\
& +\beta_{4} \cdot \text { During }_{t}+\beta_{5} \cdot \text { During }_{t} \times T M_{i}+\beta_{6} \cdot \text { During }_{t} \times S G_{i} \\
& +\beta_{7} \cdot T M_{i}+\beta_{8} \cdot S G_{i}+\epsilon_{i t} .
\end{aligned}
$$

If salience on StubHub affects other platforms, then we should reject the null hypothesis that the interaction terms coefficients $\left(\beta_{2}, \beta_{3}, \beta_{5}\right.$, and $\left.\beta_{6}\right)$ are zero.

Table 7 columns 1 \& 2 present the regression analogue of Figure 6, corresponding to the coefficients on the four interaction terms in equation (9). There is no discernible break for StubHub or Ticketmaster queries at the time of the experiment, and the effect on SeatGeek queries is positive and statistically significant. These findings suggest that the switch to BF at StubHub was market-expanding, rather than pure business-stealing.

\subsection{Seller Responses}

Our focus so far has been on consumer behavior, but changes to the buyer experience may affect seller behavior. As an example, if obfuscation increases seller profits, then more sellers may enter the marketplace. In turn, increased seller participation may bolster competition and help buyers. These sorts of externalities complicate welfare analysis in two-sided markets. 
Table 7: Listing Quality and Google Searches Following Back-end Fees

\begin{tabular}{lcccc}
\hline \hline & \multicolumn{2}{c}{ Query Index } & \multicolumn{2}{c}{ Log Listings } \\
\hline \multirow{2}{*}{ Ticketmaster $\times$ Experiment } & $(1)$ & $(2)$ & $(3)$ & $(4)$ \\
& -6.05 & -6.05 & - & - \\
SeatGeek $\times$ Experiment & $(4.00)$ & $(3.70)$ & & - \\
& 2.82 & 2.82 & - & \\
Log Position $\times$ Experiment & $(5.56)$ & $(2.51)$ & & -0.17 \\
& - & - & -0.17 & $(0.05)$ \\
Ticketmaster $\times$ Post & 4.58 & 4.58 & $(0.05)$ & - \\
& $(4.83)$ & $(4.79)$ & - & - \\
SeatGeek $\times$ Post & 0.85 & 0.85 & - & -0.15 \\
& $(6.10)$ & $(3.26)$ & & $(0.02)$ \\
Log Position $\times$ Post & - & - & -0.15 & Day \\
Fixed Effects & - & Week & - & - \\
Obs & 78 & 78 & - & $(0.02)$ \\
\hline
\end{tabular}

Notes: This table reports coefficient estimates that correspond to equation 9 . Heteroskedasticity-robust standard errors in parentheses. Observations from 06/01/2015 - 12/01/2015, at the weekly level in columns 2 and 3 and at the daily level in columns 3 and 4 . Columns 1 and 2 include main effects for Ticketmaster and SeatGeek. All regressions include main effects for Post (8/31 onwards) and Experiment (8/16-8/30).

We examine whether inventory responds to the use of BF pricing, with a focus on ticket quality. Section 5.2 shows that buyers upgrade to higher quality seats when fees are less salient, making StubHub a more attractive platform to sellers of high quality tickets. Figure 7 shows the evolution of inventory on StubHub over time by row letter. Visual inspection suggests that the relative number of seats in front rows (A-E) compared to back rows (U-Z) increase after the switch to BF. Consistent with Ellison and Ellison (2009), we find that sellers respond to the change in the buyer's experience.

To further investigate seller responses, we test for a break in listing quality during and after the experiment, when the whole site switched to BF. To measure quality, we construct a row number variable, Position, which counts the number of rows in between the seat and row A plus one (taking a value of one for seats in row A). We then construct an event study, as in equation 
Figure 7: Fraction of Listings by Row Letter

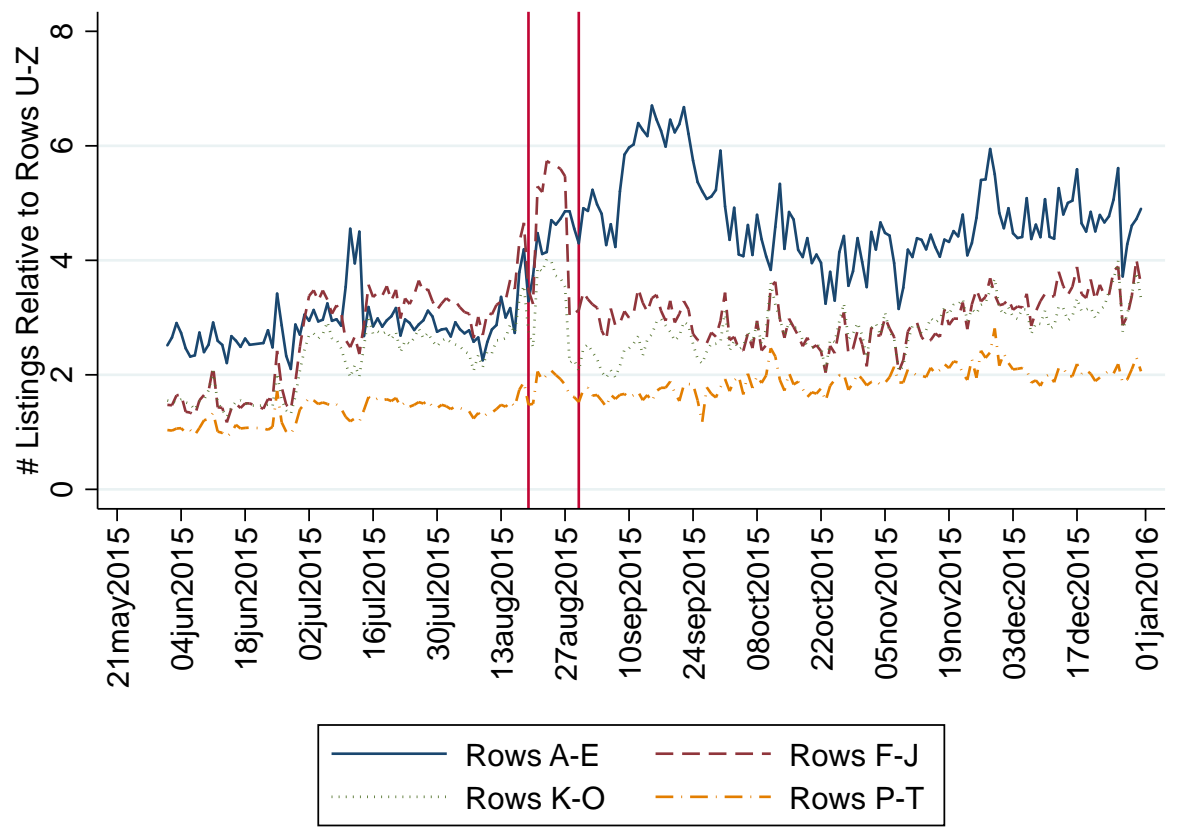

9, with a set of interactions between the log of Position and time dummies. Table 7 presents the coefficient estimates on the interaction terms, which are negative and statistically significant at conventional levels for both the experiment and its aftermath. The point estimates imply that a ticket listed on StubHub is $15 \%$ more likely to be in row A than row B following the experiment (under BF) compared to before (under UF). The increase in high quality listings underscores the complexity of platform design, as changes to one side of the market influence the entry decisions on the other.

\section{A Second Experiment: Event-Level Randomization}

The 2015 experiment randomized salience across users so that BF and UF users had the same StubHub experience, but for the addition of fees in the latter's search results. In a earlier experiment performed in 2012 at StubHub, fee salience was randomized at the event level, which presents distinct challenges, but offers a nice robustness check for the 2015 experiment. 
First, StubHub's unique inventory threatens the independence assumption for the 2015 experiment, but not for its 2012 counterpart. Suppose that price obfuscation merely accelerates, but does not actually alter, the consumer's purchase decision. In this case, BF users will tend to buy early in the 2015 experiment, which may reduce inventory for UF users. Comparing purchase probabilities without taking this censorship into account would mistakenly indicate a positive treatment effect. In other words, treating user $\mathrm{A}$ affects user B. Blake and Coey (2014) discuss this challenge on eBay. Fortunately, the 2012 experiment does not suffer from the same contamination concern because all tickets for a particular event share the same treatment status.

A second challenge that the 2012 experiment addresses is multi-device use. In the 2015 experiment, we sort users into BF or UF the first time they touch an event page on StubHub during the experiment period. StubHub employs cookies to track users, so that the user remains in the appropriate group throughout the trial. However, cookies differ across devices, and a user would be re-randomized into the BF or UF group if she used a different devise. Switching devices is particularly problematic if its incidence depends on initial treatment assignment. As an example, if UF users - upon seeing higher initial prices - delay their purchases and revisit StubHub on a second device, then the BF treatment would be positively correlated with purchasing. In the 2012 experiment, tickets to each event retain their treatment status regardless of the device that consumers use.

Finally, randomization at the event level provides additional insight into general equilibrium effects examined in section 6.4. We have shown that when StubHub alters the consumer's experience, it alters sellers' behavior. Salience might also affect price levels, which is hard to gauge given the unique inventory on StubHub. For example, if price obfuscation attracts more elastic buyers, then sellers might lower their prices. If these effects are large, then the 2015 experiment does not provide the true counterfactual of interest: what 
Table 8: 2012 Experiment Results

Back-end vs Upfront Fees

\begin{tabular}{lc}
\hline \hline & $\%$ Difference \\
\cline { 2 - 3 } Purchase Probability & $-12.38 \%$ \\
& $(6.63)$ \\
Percentile of Choice Set & \\
Selected & $-11.97 \%$ \\
& $(5.62)$ \\
\hline
\end{tabular}

Notes: This table reports coefficients estimates based on data from the 2012 StubHub experiment. Standard errors are clustered at the event level and reported in parentheses.

happens when all users face BF? Instead, the econometrician only observes what happens on StubHub when fees are shrouded for $50 \%$ of users. The 2012 experiment answers this question because a ticket-seller for a particular match faces an entirely BF or UF audience, but not a mix of both.

In the 2012 experiment, 33 out of 99 Major League Soccer Games were randomly selected for UF. Prices for tickets to these games included fees, even from the initial event page. The remaining 66 matches had the BF experience.

The results from the 2012 experiment, displayed in table 8, confirm our 2015 findings: fee salience reduces revenue substantially. Consumers are $13 \%$ less likely to buy tickets to an Upfront Fee match. The difference has a p-value of 0.076 , with standard errors clustered at the event-level.

We also examine whether users upgrade to more expensive tickets for BF games. Unfortunately, tests based on purchase prices are under-powered because of the high sampling variance across matches. To control for the unobserved popularity of matches, we test whether users purchase from the same quantile of price in BF versus UF matches. For each transaction, we calculate where the purchase ranks in a user's choice set (StubHub's entire inventory for the match at the time of purchase). On average, consumers buy

\footnotetext{
12 Note that fees were approximately $10 \%$ in 2012.
} 
Figure 8: Percentile of Choice Set Purchased in the 2012 Experiment

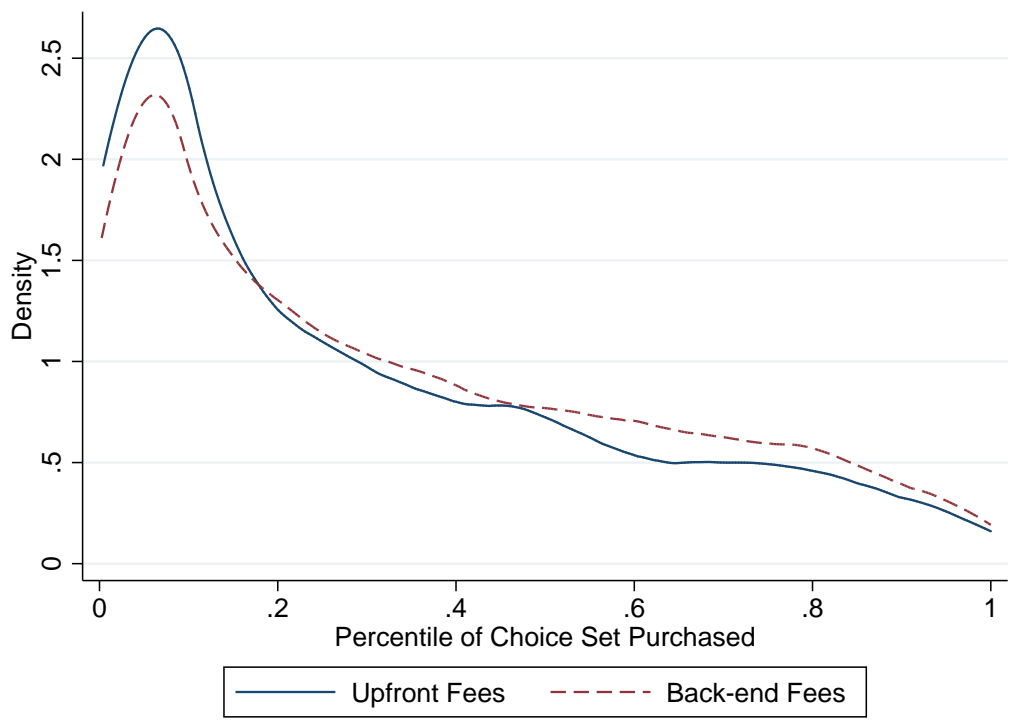

from a $12 \%$ lower quantile for UF compared to BF games. Figure 8 shows the full distribution of purchase quantiles for BF and UF matches.

While these results are heartening, we prefer the 2015 experiment for its larger sample size. Further, experimentation at the event-level suffers from a different kind of contamination bias: consumers may substitute away from UF matches (which appear more expensive) to BF matches. The 2015 experiment is not vulnerable to this type of contamination. The ability to execute two experimental designs is one advantage of the StubHub setting.

\section{Discussion}

Using data from a randomized control trial on StubHub, we find that shrouding buyer fees increases total revenue by about $20 \%$. The control group was shown fee-inclusive prices from the initial search page, while the treatment group was shown base prices until the checkout page. We decompose the impact of obfuscation into a quantity effect and a quality effect. The latter accounts for about $28 \%$ of the revenue bump because consumers upgrade to 
higher quality products when they observe lower prices initially. We find that consumers who are shown fees upfront drop off early in the purchase funnel, while those shown fees later are more likely to exit after the site displays total prices, consistent with consumer misinformation.

We find that salience persists beyond initial misinformation. Experienced users, who arguably should anticipate the fee, spend $15 \%$ more on StubHub when the fee is shrouded. More strikingly, after the platform switched to Backend Fees, the users exposed to the BF treatment during the experiment spend similar amounts to those newly exposed to Back-end Fees. This behavior suggests that experience with Back-end Fees does not give users an advantage in anticipating true final prices. These patterns suggest that salience is not a one-off phenomenon, which becomes irrelevant as consumers learn about the sales environment. It is perhaps unsurprising, if not reassuring, that we find that sellers respond to changes in the salience of the buyer experience. Sellers are more likely to list high quality tickets when fees are presented at the back-end, highlighting the nuance of salience effects on a platform.

Our results also demonstrate that price salience looms large in markets where consumers purchase only intermittently. The existing literature focuses on contexts where consumers purchase frequently, such as grocery stores in Chetty et al. (2009). In these settings, consumers plausibly hold strong beliefs about both the amount and presentation of fees and taxes ${ }^{13}$ and so we might interpret their response to an abrupt change in salience as a reaction to offequilibrium path play. In contrast, most users who visit StubHub during our experiment are new to the site. Their reactions to salience may more closely parallel reactions in markets like real estate, higher education, or automobiles, where policymakers might play a role in mandating fee disclosure.14

To underscore the magnitude of these salience effects, Table 9 presents

\footnotetext{
${ }^{13}$ Chetty et al. $(2009)$ provide survey evidence that the modal consumer in their setting identifies the correct tax level.

${ }^{14}$ E.g., starting in 2012, the Department of Transportation requires airlines to advertise fee-inclusive prices.
} 
Table 9: Fee Presentation across Platforms

\begin{tabular}{lcc}
\hline \hline Marketplace & Salience & Fee \\
\hline AirBnB & BF & 6-12\% Service Fee + Cleaning Fee* + Tax \\
DoorDash & Mix BF $/$ UF & Service Fee $(7-15 \%)+$ Delivery Fee (0.99-7.99, for non-subscribers) + Tax \\
eBay & BF & Any Shipping Fees + Sales Tax \\
Etsy & BF & Any Shipping Fees + Sales Tax (Buyer, Depending on Residency) \\
HomeAway & BF & 5-9\% Service Fee + Cleaning Fee ** + Taxes \\
Hotels.com & BF & Variable Service Fee + Taxes \\
Instacart & BF & 5\% Fee + Any Tip \\
Postmates & BF & Service Fee + Delivery Fee (3.99-5.99, for non-subscribers) \\
SeatGeek & UF & 20\% (Includes Any Delivery Fee) \\
TaskRabbit & Mix BF $/ U F$ & 15\% Upfront Service Fee + 7.5\% Back-end Trust \& Safety Fee \\
Ticketmaster & BF & $20 \%+$ (Service + Any Facility or Processing Fees) \\
\hline
\end{tabular}

Notes: Fee levels taken from platform where possible, otherwise from news articles describing the platform. The third column $(\mathrm{Fee})$ contains links to references for fee level information. Salience data collected by hand in September 2018.

information on fee levels and presentation at other online ticket retailers and decentralized marketplaces. The variation across firms is striking: while Ticketmaster uses Back-end Fees, SeatGeek defaults to Upfront Fees. Taskrabbit, a home improvement labor market, includes a $15 \%$ service fee in the upfront price, but adds a $7.5 \%$ trust and safety fee on the back-end. More work exploring the equilibrium determinants of obfuscation across industries and companies would help shed light on the use and impacts of price obfuscation. 


\section{References}

Abaluck, Jason and Jonathan Gruber, "Choice Inconsistencies among the Elderly: Evidence from Plan Choice in the Medicare Part D Program," The American Economic Review, June 2011, 101 (4), 1180-1210.

Allcott, Hunt and Dmitry Taubinsky, "Evaluating Behaviorally Motivated Policy: Experimental Evidence from the Lightbulb Market," The American Economic Review, 2015, 105 (8), 2510-2538.

Blake, Thomas and Dominic Coey, "Why Marketplace Experimentation is Harder than it Seems: The Role of Test-Control Interference," Proceedings of the 2014 ACM Conference on Economics and Computation, 2014, EC15, 567-582.

_ , Chris Nosko, and Steven Tadelis, "Returns to Consumer Search: Evidence from eBay," Proceedings of the 2016 ACM Conference on Economics and Computation, 2016, EC17, 531-545.

Bordalo, Pedro, Nicola Gennaioli, and Andrei Shleifer, "Salience and Consumer Choice," Journal of Political Economy, 2013, 121 (5), 803-843.

Brynjolfsson, Erik and Michael D. Smith, "Consumer Decision-making at an Internet Shopbot: Brand Still Matters," Journal of Industrial Economics, 2001, XLIX (4), 541-558.

Chetty, Raj, Adam Looney, and Kory Kroft, "Salience and Taxation: Theory and Evidence," The American Economic Review, September 2009, 99 (4), 1145-1177.

DellaVigna, Stefano, "Psychology and Economics: Evidence from the Field," Journals of Economics Literature, 2009, 47 (2), 315-372.

Ellison, Glenn, "A Model of Add-On Pricing," The Quarterly Journal of Economics, May 2005, $120(2), 585-637$.

- and Sara Fisher Ellison, "Search, Obfuscation, and Price Elasticities On The Internet," Econometrica, March 2009, 77 (2), 427-452.

Finkelstein, Amy, "E-Z Tax: Tax Salience and Tax Rates," The Quarterly Journal of Economics, 2009, 124 (3), 969-1010.

Gabaix, Xavier and David Laibson, "Shrouded Attributes, Consumer Myopia, and Information Supression in Competitive Markets," Quarterly Journal of Economics, May 2006, pp. 505-539.

Goeree, Michelle Sovinsky, "Limited Information and Advertising in the U.S. Personal Computer Industry," Econometrica, September 2008, 76 (5), 1017-1074. 
Greenleaf, Eric A., Eric J. Johnson, Vicki G. Morowitz, and Edith Shalev, "The Price Does Not Include Additional Taxes, Fees, and Surcharges: A Review of the Research on Partitioned Pricing," Journal of Consumer Psychology, 2016, 26 (1), 105-124.

Hossain, Tanjim and John Morgan, "...Plus Shipping and Handling: Revenue (Non) Equivalence in Field Experiments on eBay," Advances in Economic Analysis 6 Policy, 2006, 6 (2), 1-30.

Lynch, John G. Jr. and Dan Ariely, "Wine Online: Search Costs Affect Competition on Price, Quality, Distribution," Marketing Science, 2000, 19 (1), 83-103.

Morowitz, Vicki G., Eric A. Greenleaf, and Eric T. Johnson, "Divide and Prosper: Consumers' Reactions to Partitioned Prices," Journal of Marketing Research, November 1998, 35 (4), $453-463$.

Seim, Katja, Maria Ana Vitorino, and David M. Muir, "Drip Pricing When Consumers Have Limited Foresight: Evidence from Driving School Fees," Working Paper, February 2017.

Sullivan, Mary W., "Economic Analysis of Hotel Resort Fees," Economic Issues, Bureau of Economics Federal Trade Commission, 2017. 